DOI 10.37882/2223-2982.2020.11-2.10

\title{
НАУЧНЫЕ ДОСТИЖЕНИЯ АНГЛОФОННЫХ СТРАН В ЛИНГВИСТИЧЕСКОМ ПРЕЛОМЛЕНИИ
}

\section{SCIENTIFIC ACHIEVEMENTS OF ANGLOPHONE COUNTRIES VIEWED THROUGH THE PRISM OF LINGUISTICS}

O. Kulikova

Summary: The article deals with the most wide-spread modern tendencies of the English language development as the lingua franca of today's science and technology.

The author points to the international character of many scientific projects in the context of international integration. The English language is claimed to play an important role in modern term formation as well as in building the terminological base in a recipient language. Multiple examples are drawn to demonstrate the reflection of emerging scientific concepts in the lexis of English as well as other national languages. The article considers various possibilities and the results of English terms and subject related lexis assimilation in the recipient language. The author identifies research donor spheres supplying the English lexis of scientific works and findings to other languages. The prospects of the English language influence on the concept sphere as well as the industry-specific vocabulary of the Russian scientific discourse are also tackled in the article.

Keywords: the English language; lingua franca; scientific achievements; term formation; terminological base; concept sphere; assimilation; recipient language; donor sphere; Russian scientific discourse.

\section{Введение}

$\mathrm{H}$ астоящая статья посвящена наиболее заметным тенденциям в области межкультурной научной интеграции, подразумевающей, помимо прочего, отражение новых явлений, обнаруженных учеными в различных областях науки и жизни социума, а также результатов научных достижений и открытий, в словарном составе английского языка.

Сегодня справедливо говорить не только о научных прорывах, совершенных британскими исследователями, но и о научных разработках американских, австралийских, а также ученых других англофонных стран, результатами достижений которых пользуется весь мир и которые в той или иной мере находят отражение в национальных языках.

Проблема национальной принадлежности научного открытия чрезвычайно непроста. Так, нет однозначного ответа на вопрос о том, чьим изобретением является Ин-

\author{
Куликова Ольга Викторовна \\ Д.филол.н., профессор, Московский государственный \\ институт международных отношений \\ (Университет) МИД России \\ ok517@yandex.ru
}

Аннотация: В статье рассматриваются наиболее распространенные на сегодняшний день тенденции развития английского языка как lingua franca современной науки и техники. Отмечается интернациональный характер многих научных проектов в условиях международной интеграции. Подчеркивается роль английского языка в современном терминообразовании, а также в формировании терминологической базы языка-реципиента. На многочисленных примерах демонстрируется отражение возникающих научных понятий в лексике английского и других национальных языков. Рассматриваются возможности и результаты ассимиляции англоязычных терминов и предметно-релевантной лексики в принимающем языке. Выявляются исследовательские области-доноры, поставляющие англоязычную лексику научных разработок и открытий в другие языки. Затрагивается вопрос о перспективах влияния английского языка на концептосферу и словарный состав некоторых отраслей русскоязычного научного дискурса.

Ключевые слова: английский язык; lingua franca; научные достижения; терминообразование; терминологическая база; концептосфера; ассимиляция; язык-реципиент; область-донор; русскоязычный научный дискурс.

тернет (всемирная система объединённых компьютерных сетей для хранения, обработки и передачи информации) - без преувеличения, главный технологический прорыв последних десятилетий. Вопрос авторства этого изобретения - запутанная история, в его создании принимали участие многие блестящие учёные и коллективы целых университетов (Массачусетского, Калифорнийского, а позднее - университеты Великобритании и Норвегии). При этом слово, обозначающее данное явление, имеет английское происхождение, оно прочно вошло в языки мира, в том числе и в русский.

\section{Ассимилячия англоязычных терминов в языке-решипиенте}

В начале 1990-х годов английский физик и программист Тим Бернерс-Ли начал работу над открытой системой, которая позволяла бы размещать в сети различные данные таким образом, чтобы любой пользователь мог иметь к ним доступ. Изначально планировалось, что эта система позволит обмениваться нужной информацией 
учёным-физикам. Так появилась хорошо знакомая нам глобальная сеть - World Wide Web (WWW) ${ }^{1}$ или, как мы ее называем, Всемирная паутина. Все термины, связанные с этой областью и слова, претерпевшие детерминологизацию, преимущественно англоязычного происхождения, самые распространенные из них: веб-сайт; браузер; аккаунт; бан (от англ. bап - запрещать); блог; блогер; биткойн; файл; доменное имя (Әомен); Интернет-сервер; интерфейс; клик; контент; куки; логин; онлайн / оффлайн и производные от них; сайт; сервер; спам; тизер; трафик; хостинг и многие другие. В большинстве случаев, русский язык принял и ассимилировал эти слова не в силу отсутствия эквивалентов (во многих случаях они есть: клик - щелчок, контент - содержание), но в силу того, что интернет-среда, во-первых, быстро пополняется новыми лексическими поступлениями, чаще всего англоязычного происхождения, быстро входящими в обиход пользователей, и во-вторых, в силу того, что сама эта среда во многом предполагает межнациональное и даже наднациональное общение, требующее общности основных понятий и соответствующих им лексических единиц ${ }^{2}$.

Что касается степени ассимиляции, то она может быть полной или частичной. Это, прежде всего, касается написания: так, слово «Интернет», войдя в русский язык, строго писалось с заглавной буквы, однако сейчас встречается написание со строчной. Склонение слова «Интернет» уже не вызывает нареканий со стороны специалистов в области русского языка (возможно, не всех). «Офрфлайн» - обычно пишется с двумя «ффф», но, вероятно, одна буква «ф» отпадет, так же, как в слове «офис», которое на этапе его вхождения в русскоязычный дискурс писалось с двумя «ф». Сюда же относится и лексема «блогер»- с одной буквой «г» в русской версии и удвоенной " $g$ " в английском в соответствии с требованиями правописания современного английского языка. Сохранившее в русском языке свою оригинальную форму название поисковой системы Google привело к возникновению в русском интернет-жаргоне глагола «погуглить», то есть поискать информацию в поисковой системе Google. И, наконец, Zoom и зуммеры - теперь это все те, кто существует в виртуальной среде при помощи данной платформы, название которой построено на реализации по крайней мере двух из многочисленных его значений и отсылает как к эффекту «наезда камеры» из области кино, т.е. к электронному увеличению изображения, так и к американскому слэнговому слову, обозначающему «получать бесплатно».

Интересно отметить межязыковой концептуальный перенос - так, с приходом эры Интернет в русскоязычном дискурсе довольно широко распространилось понятие «сеть». И если Интернет сохранил свою оригинальную форму, то такие понятия, как «сетевая экономика», «сетевые университеты» существуют в своей русскоязычной версии.

\section{Lingua franca современной науки и техники}

Вопрос о национальных границах науки весьма широко обсуждается мировой научной (и не только) общественностью. Несмотря на то, что каждая страна стремится «записать на свой счет» успехи в той или иной научной области, наука сегодня как никогда является интернациональной: благодаря современным технологиям информация относительно возникающих научных гипотез, исследованиях и их результатах с легкостью пересекает границы; широко распространенной тенденцией стала совместная работа международных коллективов ученых. Принцип временных международных команд оказывается полезным не только для научно-исследовательской организации, инициировавшей научные разработки в определенной области, но и для членов международной команды, так как обусловливает приобретение ими новых знаний и опыта, наработку навыков, расширение профессиональных связей. Профессиональное общение между членами международной команды чаще всего происходит на английском языке, во всем мире признающимся lingua franca современной науки и техники. Данный статус английского языка означает не только стабильное использование англоязычных терминов в научной и технической областях, равно как и в сфере повседневного общения, но и появление в результате научной работы англоязычных команд новой англоязычной терминологии и научных публикаций на английском языке.

По мере работы над совместным проектом члены команды вырабатывают оптимальные подходы к решению задач определенной категории, то есть обучаются в процессе научной деятельности, что способствует дальнейшему формированию системы профессионально релевантных компетенций каждого из них [Куликова 2013]. Данный вывод находит подтверждение в наблюдениях автора исследования временных команд, отмечающего, что «самые тонкие места временных проектных команд могут оказаться и самыми сильными - как для организации, так и для самих специалистов» [Эдмондсон 2012, с.66]. К этой категории, вероятно, можно отнести необходимость освоить и использовать общий - английский - язык в процессе межкультурной научной коммуникации, что способствует не только личностному и профессиональному росту исследователя, но и вносит вклад в развитие концептуальной и терминологической базы многих предметных областей.

\footnotetext{
1 Источник: https://usamagazine.ru/kto-i-kogda-sozdal-internet/

2 Вместе с тем, «мышка» в русскоязычном интернет-дискурсе прижилась русская, а не английская «тоuse».
} 
Английский язык, как lingua franca науки, техники, изобретательства сегодня лидирует среди других коммуникативно значимых языков в области терминообразования. Ученые признают, что концептуальные системы имеют страновые различия, то же относится и к различным компаниям, часто пользующимся «своей» терминологией, что чревато коммуникативными срывами в сфере профессионального общения [Terminology in Everyday Life 2010]. Вместе с тем, преобладание английского языка способно предотвратить вероятные риски коммуникативных провалов и обеспечить унификацию отраслевой терминологии.

\section{Нейминг в ангАийском языке и «принимаюших» языках. Терминологические сферы-Аоноры и сферы-решипиенты}

Обычно наименование нового концепта - это прерогатива его автора. Процесс наименования концепта разработчиком соответствующего новшества получил название первичного нейминга. Как отмечают специалисты в области терминоведения, сегодня первичный нейминг происходит преимущественно на английском языке, что связано, как отмечалось выше, с ролью английского как lingua franca в современном мире науки и техники. Английский признается языком-источником для большинства терминологических неологизмов в других языках. Термин, который обозначает концепт в языке-реципиенте, но при этом уже имеет название в английском языке (или другом языке-источнике), представляет собой продукт вторичного нейминга [Why is terminology...2014, p.33].

Образование новых терминов обусловливается новейшими достижениями в области науки и техники. Сам термин «инновация» происходит от латинского «novatio», что означает «обновление» (или «изменение»), и приставки «іn», которая переводится с латинского как «в направление». Если переводить дословно, «innovatio» pyfxbn «в направлении изменений». Само понятие innovation впервые появилось в научных исследованиях XIX века. Новую жизнь понятие «инновация» получило в начале XX века в научных работах австрийского и американского экономиста Й. Шумпетера в результате анализа «инновационных комбинаций» - изменений в развитии экономических систем. Шумпетер был одним из первых учёных, кто в 1900-х гг. ввёл в научное употребление данный термин в экономике.

Некоторые инновационные понятия уже описаны, названы и введены в научный обиход английскими исследователями, но еще не все из них получили названия в национальных языках. Следующие примеры ${ }^{3}$ из области астрономии представляются наименее проблематичными с точки зрения их перевода, например, на русский:

red geyser (a galaxy that contains a large number of very large black holes and where no new stars are able to form): Today, astronomers ... are announcing the discovery of a new class of galaxies called "red geysers" that harbor supermassive black holes with winds that have the power to keep dormant galaxies quiet [Astronomy magazine, 25 May 2016];

dark sunshine (a substance thought to exist inside the sun that gives off a special type of light): While scientists continue looking skyward to find more insight into the mysteries of dark matter, some have begun looking to our sun for "dark sunshine" [Astronomy magazine, 25 May 2016];

space fever (a medical condition in which an astronaut's body temperature is higher than usual because of the effects of weightlessness): "This space fever, as we may call it, has potential implications for long-term space flights in terms of astronauts' health, wellbeing and support," the researchers wrote in their study, published in the journal Scientific Reports [www.independent.co.uk, 6 January 2018].

Интересным с точки зрения лингвокультурологии представляется не так давно вошедший в широкое употребление медицинский термин «London throat» (a mild infection, similar to a cold, said to be common among people who live in London and caused by pollution): Scrapping speed bumps could help protect city dwellers against "London throat" because braking releases toxic dust which may trigger coughs and colds, scientists have said. Urbanites often suffer from intermittent bouts of runny noses and brain fog, which experts have long-suspected are caused by pollution. Dubbed "London Throat", this ongoing low-level illness can lead to more serious infections such as pneumonia and bronchitis [telegraph.co.uk, 9 January 2020].

В области экономики лексические нововведения последнего времени в основном отражают явления, понятные и узнаваемые членами социума, например:

attention economy (an economic system where the amount of information available on the internet means that companies must compete to attract the attention of potential consumers): As $63 \%$ of marketers world-wide set out to increase traffic and leads over the next 12 months, their first instinct will be to produce more content. Fight this instinct. Remember, we are living in an attention economy. The way to get attention today isn't to shout more or shout louder; instead, think carefully about how you can use these 8 strategies to help people better navigate the information deluge [www.thinkgrowth.org, 20 June 2017];

surveillance capitalism (an economic system where a company, usually a website, makes money by selling its users' personal data to other companies): Google and Facebook, in particular, are avatars and practitioners of the new

3 Здесь и далее примеры контекстов употребления лексических единиц приводятся со страниц сайта Cambridge Dictionary [https://dictionary.cambridge.org/]. 
"surveillance capitalism", the system whereby it is not our need for goods and services that creates the greatest corporate wealth, but the data we generate that can then be sold on [The Sunday Telegraph, 4 February 2018];

experience economy (an economic system that is based on people doing things, such as taking part in sporting activities and visiting places, rather than buying things): A series of studies is revealing strange things about our spending habits. They call it the "experience economy", which gives it the sense of a grand theory. And there is science behind it, but it's also very simple: regardless of political uncertainty, austerity and inflation, we are spending more on doing stuff, choosing instead to cut back on buying stuff [The Guardian, 13 May 2017].

Сегодня английский язык фиксирует проникновение в область экономики вопросов из самых разных областей жизни общества, например, вопросов гендерного равноправия, в результате чего появляются такие гибридные лексические единицы, как womenomics (the activities undertaken by a government to enable more women to enter the workforce, especially into high-level job): For those who have already decided that Japan's "womenomics" movement is an empty promise, the Kanagawa Women's Empowerment Support Group has plenty of ammunition. Its pinktoned website introduces a panel of movers and shakers aiming to promote female empowerment in Kanagawa prefecture in the coming year: 11 high-profile corporate leaders - and all 11 of them men [Financial Times, 8 March 2017]. Очевидно, что переход подобной лексики в русский язык пока возможен лишь благодаря описательному переводу, предоставляющему толкование обозначаемого англоязычным термином явления. В то же время английская лексема money-laundering вошла в русский и через прием калькирования превратилась в очень «удобное» с точки зрения узуса отмывание денег.

Углубленные разработки англоязычного научного сообщества в области экологии и устойчивого развития привнесли в другие языки, включая русский, «зеленую» тематику. В общественном сознании зеленый и салатовый цвета связаны с органическим происхождением продукта, а если говорить о политике и стратегии компании, то зеленый связывается с защитой окружающей среды, сохранением природных ресурсов и здоровья человека. Сегодня мы встречаем в русском языке «зеленые товары», «зеленый рынок», «зеленые офисы», просто магазин экологических товаров «Зеленый» и даже «экологичный зеленый железнодорожный транспорт». Английский язык изобилует «экологической» лексикой, несущей преимущественно положительную коннотацию: green marketing (совокупность маркетинговых действий, направленных на продвижение экологически чистой продукции); green consumerism (тенденция к употреблению таких продуктов, производство которых является экологичным); green cloud (цифровой сервис, связанный с хранением и предоставлением вычислительных опе- раций на удаленных облачных серверах; сервис с потенциально выигрышной услугой для общества по сравнению с традиционными услугами подобного рода).

Однако при этом отмечаются попытки использовать обозначения цвета «зеленый» для осуществления не совсем благовидных практик. Так, в статье под заголовком «"Зеленый пиар" - как бренды притворяются "эко"» рассматривается явление под названием «гринвошинг».

Термин «гринвошинг» образован из комбинации английских слов green (зеленый, экологичный) и whitewashing (отбеливание). В буквальном переводе greenwashing - «зеленое отмывание» или «зеленый камуфляж». Использовать его предложил американский биолог и журналист Джей Вестервельд. В 1983 году во время исследовательской поездки по островам Фиджи он обратил внимание на необычную «зеленую» практику. Администрация крупного отеля Beachcomber Resort советовала постояльцам повторно использовать полотенца и постельное белье, чтобы снизить вред, наносимый коралловым рифам. На самом деле сотрудники отеля беспокоились только о сокращении расходов на стирку. В 1986 году Вестерфельд описал эту практику в своем эссе, после чего новый термин распространился в прессе и вошел в широкий обиход. Однако сам прием грнвошинга оказался не новым: задолго до описанного случая нефтяная компания Chevron выпустила рекламу о том, как спасает бабочек и морских черепах. Эффективность роликов принесла компании престижную рекламную премию Effie. А экологи назвали эту рекламу «золотым стандартом» гринвошинга, поскольку в то время компания Chevron нелегально сбрасывала токсичные отходы в места обитания диких животных (по материалам [https:// style.rbc.ru/health/5e0124cf9a79479754070489]).

Такие области, как устойчивое развитие, экология, охрана окружающей среды, сегодня характеризуются возникновением многочисленных новых понятий, первичный нейминг которых обеспечивается английским языком. Новым понятиям соответствуют лексические единицы, обретающие новое значение в контексте наиболее актуальных проблем существования человечества, примером чему может служить термин ecotherapy - экотерапия - общий термин для целого ряда направлений психологической поддержки, которые используют эмпирические связи с природой. Как отмечают исследователи, современный английский язык закрепляет и пропогандирует экоцентризм как новую модель взаимодействия человека и природной среды [Басинская 2019, с. 6], что, как мы видим, находит отражение и в русском языке.

Кроме того, появление в результате научно-исследовательской и предпринимательской деятельности такого обилия понятий и соответствующих им языковых единиц способствует развитию и относительного нового 
направления в лингвистике - эколингвистики.

Становление интернет-коммуникации, интернет-дискурса и, соответственно, языка виртуальной среды дало мощный толчок развитию новых исследований, в частности, в российской лингвистике. Исследованиям подвергается такая проблематика, как:

- виртуальная дискурсивная практика и характерный для нее эффект стаккато (способ быстрого сканирования кратких фрагментов текста из многочисленных интернет-источников);

- особенности языковой личности в виртуальном пространстве (эффект зеркала в интернет-коммуникации);

- интернет-коммуникация и ее взаимодействие с дискурсами различных типов;

- языковая специфика интернет-коммуникации (напр., интернет-речь и эффект эсперанто; особенности языка блогеров);

В лингводидактике мы занимаемся исследованием когнитивно-психологических особенностей поколения миллениалов, то есть поколения Интернет (или поколений Y and Z) в поисках наиболее оптимальных подходов и способов обучения представителей этого поколения иностранным языкам [Белогаш, Мельничук 2020].

\section{ЗакАючение}

Итак, даже очень беглое рассмотрение основных тен- денций подтверждает общепризнанное мнение о том, что английский язык науки и техники продолжает играть важнейшую роль в пополнении словаря национальных языков, в том числе и русского:

- по-прежнему происходит формирование определенного пласта терминологии на основе англоязычных терминов, соответствующих новым концептам, появившимся в результате открытий и разработок англоязычных ученых;

- в современном мире это, преимущественно, результаты коллективной работы, имеющие несколько авторов;

- научные и технические нововведения, появившиеся в англоязычном научном поле, проходят стадию первичного нейминга и закрепляются в англоязычном узусе;

- новая англоязычная лексика из научно-технической области, попадая в лексическую базу языкареципиента, ассимилируется в языке полностью или частично;

- за счет подобных поступлений происходит расширение концептуальной сферы различных областей принимающего (в нашем случае, русскоязычного) дискурса;

- наиболее продуктивными сферами-донорами, поставляющими англоязычную лексику и новые понятия в русскоязычный дискурс, являются коммуникативные технологии, экология и защита окружающей среды, экономика, устойчивое развитие.

\section{ЛИТЕРАТУРА}

1. Басинская М.В. Современные номинативные процессы в англоязычном экологическом дискурсе: автореф.дис. ... канд.филол.наук. М., 2019.24 с.

2. уликова 0.В. Междисциплинарность как базовый принцип формирования системы профессионально релевантных компетенций в сфере экономики и бизнеса // Экономика языка и бизнес: сб.науч.тр. - М.:ФГБОУ ВПО МГЛУ, 2013. - С. 64 - 73.

3. Смирнова У. “Зеленый пиар” - как бренды притворяются “эко”, 2019. URL: https://style.rbc.ru/health/5e0124cf9a79479754070489

4. Эдмондсон Э. Как делать то, что никто никогда не делал // Harvard Business Review — Россия. - Май 2012. - c. 62 - 71.

5. Terminology in Everyday Life / Ed. by Marcel Thelen and Frieda Steurs. - John Benjamins Publishing Co, 2010 - 281 p.

6. Why is terminology your passion? A collection of interviews with prominent terminologists. - European Union, 2014. - $116 \mathrm{p}$.

7. Белогаш М.А., Мельничук М.В. Когнитивные аспекты развития информационно-образовательной среды в высшей школе в эпоху цифровизации //Российский гуманитарный журнал. 2020. Т. 9. № 2. С. 123-132.

8. https://usamagazine.ru/kto-i-kogda-sozdal-internet/

9. https://dictionary.cambridge.org/

○ Куликова Ольга Викторовна (ok517@yandex.ru).

Журнал «Современная наука: актуальные проблемы теории и практики» 